\title{
Combined primary carnitine deficiency with neonatal intrahepatic cholestasis caused by citrin deficiency in a Chinese newborn
}

\author{
Yiming Lin ${ }^{1 \dagger}$, Weihua Lin ${ }^{1 \dagger}$, Yanru Chen ${ }^{1}$, Chunmei Lin ${ }^{1}$, Zhenzhu Zheng ${ }^{1}$, Jianlong Zhuang ${ }^{2^{*}}$ and Qingliu Fu ${ }^{1 *}$ (D)
}

\begin{abstract}
Background: Primary carnitine deficiency (PCD) is an autosomal recessive disorder affecting the carnitine cycle and resulting in defective fatty acid oxidation. Neonatal intrahepatic cholestasis caused by citrin deficiency (NICCD) is an autosomal recessive disorder and one of the main causes of inherited neonatal cholestasis. Both PCD and NICCD are included in the current expanded newborn screening (NBS) targets.

Case presentation: Targeted exome sequencing was performed on a Chinese proband, and Sanger sequencing was utilised to validate the detected mutations. The patient who was initially suspected to have PCD based on the NBS results presented with neonatal intrahepatic cholestasis and ventricular septal defect. Further investigations not only confirmed PCD but also revealed the presence of NICCD. Four distinct mutations were detected, including c.51C > G (p.F17L) and c.760C > T (p.R254X) in SLC22A5 as well as c.615 + 5G > A and IVS16ins3kb in SLC25A13.

Conclusions: This is the first reported case of PCD and NICCD occurring in the same patient. The dual disorders in a newborn broaden our understanding of inherited metabolic diseases. Thus, this study highlighted the importance of further genetic testing in patients presenting with unusual metabolic screening findings.
\end{abstract}

Keywords: Primary carnitine deficiency, Neonatal intrahepatic cholestasis caused by citrin deficiency, Newborn screening, Intrahepatic cholestasis, Ventricular septal defec

\section{Background}

Primary carnitine deficiency (PCD, OMIM \#212140) is an autosomal recessive disorder of fatty acid oxidation caused by mutations in the SLC22A5 gene [1]. PCD is characterized by an estimated prevalence of 1:40,000-1: 120,000 [2], with an extremely high frequency of 1:300 in the Faroe Islands [3]. Patients with PCD can suffer from skeletal or cardiac myopathy, muscle weakness, and hepatic encephalopathy [2]. Moreover, PCD patients have a lifetime risk of sudden death if left untreated [4].

\footnotetext{
*Correspondence: 415913261@qq.com; wrightlym@sina.com

†Yiming Lin and Weihua Lin contributed equally to this work.

${ }^{2}$ Prenatal Diagnosis Center, Quanzhou Maternity and Children's Hospital, 700

Fengze Street, Quanzhou 362000, Fujian Province, China

${ }^{1}$ Neonatal Disease Screening Center, Quanzhou Maternity and Children's

Hospital, 700 Fengze Street, Quanzhou 362000, Fujian Province, China
}

PCD can be identified during newborn screening (NBS) by measuring free carnitine (C0) levels in dried blood spots [5]. Early diagnosis and treatment can prevent metabolic decompensation and possible death.

Neonatal intrahepatic cholestasis caused by citrin deficiency (NICCD, \#OMIM 605814) is an autosomal recessive disorder caused by biallelic SLC25A13 mutations [6]. NICCD is a pan-ethnic disorder with a high prevalence in East Asian populations. The incidence of NICC $\mathrm{D}$ in Japan is estimated on the basis of a carrier ratio (1: 65) and is equal to 1:17,000 [7]. Our previous study, combined with genetic screening, revealed that the frequency of NICCD in five Chinese NBS programs was 1:26403 [8]. Patients with NICCD are characterised by neonatal intrahepatic cholestasis, hyperbilirubinemia, hepatomegaly, and variable liver dysfunctions, including fatty liver disease [9].

(c) The Author(s). 2020 Open Access This article is licensed under a Creative Commons Attribution 4.0 International License, which permits use, sharing, adaptation, distribution and reproduction in any medium or format, as long as you give appropriate credit to the original author(s) and the source, provide a link to the Creative Commons licence, and indicate if changes were made. The images or other third party material in this article are included in the article's Creative Commons licence, unless indicated otherwise in a credit line to the material. If material is not included in the article's Creative Commons licence and your intended use is not permitted by statutory regulation or exceeds the permitted use, you will need to obtain permission directly from the copyright holder. To view a copy of this licence, visit http://creativecommons.org/licenses/by/4.0/ The Creative Commons Public Domain Dedication waiver (http://creativecommons.org/publicdomain/zero/1.0/) applies to the data made available in this article, unless otherwise stated in a credit line to the data. 
With timely treatment, the onset of NICCD usually resolves spontaneously before 1 year of age. However, few patients may present with severe hyperammonemia, hepatic encephalopathy, and liver failure, even requiring liver transplantation [10]. The elevated citrulline levels characteristic of NICCD can be detected by tandem mass spectrometry (MS/MS) during NBS. However, currently, such screening is not optimal due to the occurrence of false negatives $[8,11]$.

Here, we report a newborn who was initially suspected to have PCD based on the NBS results. Further investigations not only confirmed that the patient had PCD but also revealed the presence of NICCD. As a result, the biochemical, genetic, and clinical features of dual-inherited metabolic diseases were described in this patient.

\section{Case presentation}

\section{Case report}

This study was approved by the Ethics Committee of Quanzhou Maternity and Children's Hospital. Written informed consent was obtained from the parents of the patient regarding the participation in the study as well as the use of obtained medical data for scientific research and publication. The proband was born by normal delivery at a gestational age of 41 weeks and 1 day, and her weight at birth was $3450 \mathrm{~g}$. She was the first child of non-consanguineous parents originating from China. There was no significant family history of inherited metabolic diseases. NBS was performed on dried blood spots of the proband on day 5 of life via ACQUITY TQD MS/MS (Waters, Milford, MA, USA).

The initial NBS results showed that the patient had an extremely low C0 level equal to $3.49 \mu \mathrm{mol} / \mathrm{L}$. The subsequent auxiliary biochemical tests confirmed the very low $\mathrm{CO}$ level; however, they additionally revealed an abnormally high concentration of citrulline. Elevation of multiple amino acid levels, including methionine, arginine, and phenylalanine, was also observed. Moreover, serum total bile acid, total bilirubin, and direct bilirubin levels were significantly elevated, indicating the existence of cholestasis. Serum $\alpha$-fetoprotein level was far beyond the reference range (Table 1) and the cardiac ultrasound revealed a ventricular septal defect (VSD) in the newborn.

Table 1 The biochemical, genetic, and clinical features of patient with PCD and NICCD

\begin{tabular}{|c|c|c|c|c|c|c|}
\hline Patient's information & $5 \mathrm{~d}$ (NBS) & $18 \mathrm{~d}$ & $26 \mathrm{~d}$ & $45 \mathrm{~d}$ & $79 \mathrm{~d}$ & Reference range \\
\hline $\mathrm{CO}(\mu \mathrm{mol} / \mathrm{L})$ & 3.5 & 3.5 & 54.5 & 14.6 & 36.4 & $8.5-50$ \\
\hline Citrulline $(\mu \mathrm{mol} / \mathrm{L})$ & 28.8 & 277.2 & 565.6 & 73 & 51.5 & $6.0-34$ \\
\hline Citrulline/Arg & 3.2 & 4.3 & 5.3 & 1.5 & 1.5 & $0.3-6.5$ \\
\hline Citrulline/Phe & 0.7 & 2.5 & 5.7 & 1.2 & 1 & $0.05-0.7$ \\
\hline Methionine $(\mu \mathrm{mol} / \mathrm{L})$ & 28.2 & 69 & 231 & 66.4 & 42 & $8-38$ \\
\hline Arginine $(\mu \mathrm{mol} / \mathrm{L})$ & 9 & 64.1 & 106.9 & 49.1 & 35.3 & $1-50$ \\
\hline Phenylalanine $(\mu \mathrm{mol} / \mathrm{L})$ & 43.7 & 111.6 & 99.3 & 59.3 & 50.7 & 20-100 \\
\hline Total bile acid $(\mu \mathrm{mol} / \mathrm{L})$ & & & 182.6 & 18.9 & 35.9 & $0-10$ \\
\hline Total bilirubin $(\mu \mathrm{mol} / \mathrm{L})$ & & & 339.8 & 226.8 & 37.7 & $5.1-19$ \\
\hline Direct bilirubin $(\mu \mathrm{mol} / \mathrm{L})$ & & & 31.8 & 18.2 & 15.9 & $0-6.8$ \\
\hline $\mathrm{ALT}(\mathrm{U} / \mathrm{L})$ & & & 33 & 16 & 34 & $0-40$ \\
\hline AST (U/L) & & & 84 & 27 & 47 & $0-40$ \\
\hline$\gamma-\mathrm{GT}(\mathrm{IU} / \mathrm{L})$ & & & 151 & 128 & 216 & $0-50$ \\
\hline Ammonia $(\mu \mathrm{mol} / \mathrm{L})$ & & & 47 & & & $10-47$ \\
\hline a-Fetoprotein $(\mathrm{ng} / \mathrm{mL})$ & & & $60,786.7$ & $82,407.8$ & $23,101.1$ & $0-8.1$ \\
\hline Total protien $(\mathrm{g} / \mathrm{L})$ & & & 41.5 & 44.4 & 47.5 & $60-80$ \\
\hline Hemoglobin (g/L) & & & & 95 & & $110-116$ \\
\hline Blood sugar (mmol/L) & & & 4.2 & 4.6 & 5 & $3.8-6.1$ \\
\hline CK (IU/L) & & & 63 & & & $26-174$ \\
\hline CK-MB (U/L) & & & 15 & & & $0-35$ \\
\hline Genotype & \multicolumn{6}{|c|}{ SLC22A5: c.51C > G + c.760C > T, SLC25A13: c.615 + 5G > A + IVS16ins3kb } \\
\hline Clinical presentations & \multicolumn{6}{|c|}{ Intrahepatic cholestasis, ventricular septal defect } \\
\hline
\end{tabular}

NBS newborn screening, $d$ day, $C O$ free carnitine, $A L T$ alanine transaminase, $A S T$ aspartate transaminase, $\gamma$-GT gamma-glutamyl transpeptidase, $C K$ creatine phosphokinase, $C K-M B$ creatine kinase isoenzyme 


\section{Genetic analysis and targeted NGS}

Genetic testing was performed by Hangzhou Genuine Clinical Laboratory Co. Ltd. (Zhejiang, China). Genomic DNA was extracted from whole blood of the proband and her parents using a Qiagen DNA Blood Mini Kit (Qiagen', Hilden, Germany). The DNA was subjected to NGS targeting a gene panel of 94 genes known to be associated with inherited metabolic diseases. The list of tested genes is included in the Supplementary material (Table S1). Then, Sanger sequencing was carried out to establish carrier status and confirm the detected alleles. Genetic testing showed the presence of four distinct mutations, including c.51C > G (p.F17L) and c.760C > T (p.R254X) in SLC22A5 as well as c.615 + 5G > A and IVS16ins3kb in SLC25A13. All four mutations have previously been described as pathogenic in patients with PCD or NICCD [12, 13]. Sanger sequencing analysis confirmed that c.51C $>$ G (p.F17L) and IVS16ins3kb were inherited from the father of the patient, while c.760C > T (p.R254X) and c.615+ $5 \mathrm{G}>\mathrm{A}$ were inherited from her mother (Fig. 1). As a result, the patient was diagnosed with PCD combined with NICCD. Following the diagnosis, L-carnitine supplementation $(150-300 \mathrm{mg} / \mathrm{kg} /$ day) was initiated, and breastfeeding was switched to a galactose-free and medium-chain triglyceride (MCT)-enriched formula. The biochemical and metabolic indicators gradually returned to normal levels after treatment.

\section{Discussion and conclusions}

This study examined a newborn with an extremely low C0 level at NBS indicating PCD. It is interesting that the subsequent tests not only confirmed the reduced level of C0 but also revealed the elevated levels of multiple amino acids, particularly citrulline. Further biochemical tests showed abnormal liver function and cholestasis, indicating the presence of a second inherited metabolic disease. Molecular genetic analysis confirmed that the patient was affected by both PCD and NICCD. Thus, this study highlighted the importance of further genetic testing in patients presenting with unusual metabolic screening findings.

The persistently low $\mathrm{C} 0$ levels accompanied by the reduction of multiple acylcarnitine levels in the newborn, increased significantly after L-carnitine supplementation. Notably, the amino acid profile was normal at the time of NBS, and markedly elevated citrulline levels were not observed until the recall phase. If the additional testing was not performed due to suspicion of PCD, the patient with NICCD would have been missed in routine NBS. As our previous study revealed, more than half of the NICCD patients were missed in the MS/MS-based NBS program [8]. Therefore, incorporating genetic screening into the current NBS program can greatly improve the diagnosis of NICCD. A previous study has shown that high tyrosine levels in NICCD patients are associated with poor prognosis [14], whereas the tyrosine levels of our patient were consistently normal. All detected mutations in SLC22A5 and SLC25A13 are known to occur at high frequency in the Chinese population. The c.760C > T (p.R254X) in SLC22A5 was previously reported as a founder mutation in the southern Chinese population [15], and IVS16ins3kb in SLC25A13 is the second most common mutation in China [16].

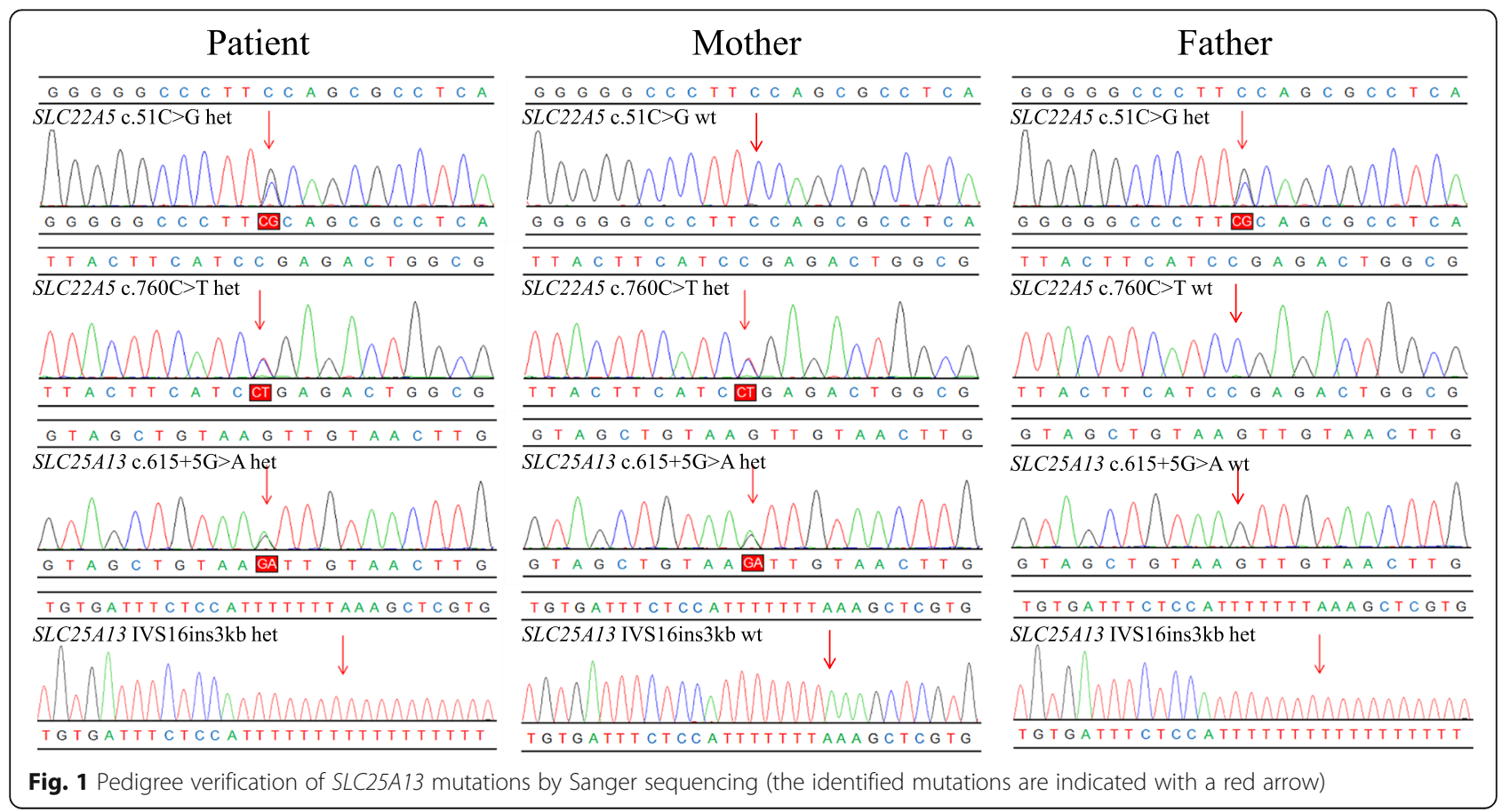


Although both PCD and NICCD have a relatively high incidence in the Chinese population [17], these disorders rarely coexist in the same individual. To our knowledge, this is the first reported case of PCD and NICCD occurring in the same patient. Popek et al. reported a newborn diagnosed with glutaric aciduria type I combined with isobutyryl-CoA dehydrogenase deficiency; however, the latter is only a benign condition that does not require treatment [18]. By comparison, both of the diseases co-occurring in our patient were relatively serious. PCD is associated with cardiomyopathy and cardiac arrhythmia [19], while NICCD is correlated with liver disease [20]. The combination of inherited metabolic diseases may aggravate the clinical phenotype of the patient. Fortunately, early medical intervention leads to the long-term favourable prognosis of PCD. Consistent with previous studies [21], the main clinical presentation of the patient in this study was neonatal intrahepatic cholestasis. In addition, the patient had VSD, one of the most common congenital cardiac diseases in infants [22]. VSD is considered to have a relatively benign clinical course; however, sudden death can also occur in some cases [23]. To our knowledge, VSD has not been reported in patients with $\mathrm{PCD}$, and this association remains unclear. Therefore, a long-term follow-up including the assessment of heart and liver function is necessary.

In summary, this study reported the first patient with both PCD and NICCD. The patient had extremely low C0 levels accompanied by a normal amino acid profile during NBS. The subsequent tests revealed neonatal intrahepatic cholestasis and VSD. Such dual disorders in a newborn broaden our understanding of inherited metabolic diseases. Thus, a long-term follow-up on the case is essential and is currently being performed.

\section{Supplementary information}

Supplementary information accompanies this paper at https://doi.org/10. 1186/s12887-020-02372-7.

Additional file 1: Table S1. The list of targeted genes

\section{Abbreviations \\ PCD: Primary carnitine deficiency; CO: Free carnitine; NBS: Newborn screening; NICCD: Neonatal intrahepatic cholestasis caused by citrin deficiency; MS/MS: Tandem mass spectrometry; NGS: Next-generation sequencing; VSD: Ventricular septal defect}

\section{Acknowledgements}

We thank the patient and her family for their participation. We would like to thank Editage (www.editage.cn) for English language editing.

\section{Authors' contributions}

YL designed the study, performed experimental work, wrote the paper, and conducted a literature review. WL assisted with data collection and reviewed as well as revised the manuscript. $Y C, C L$, and $Z Z$ examined the patients and collected the clinical data. JZ carried out the genetic tests, mutation analysis, and edited the manuscript. QF designed the study. All authors have read and approved the final manuscript.

\section{Funding}

This study was supported by grants from the Fujian Provincial Natural Science Foundation of China (Grant No. 2020 J01130 to Yiming Lin) and the Quanzhou Municipal Science and Technology Plan Project (Grant No. 2018N091S to Weihua Lin). The role of the funding body was to sponsor the two-generation pedigree analysis, the NGS, and other tests we conducted on the course of this study.

\section{Availability of data and materials}

The datasets used and/or analysed during the current study can be obtained from the corresponding author upon a reasonable request.

\section{Ethics approval and consent to participate}

This study was approved by the Ethics Committee of the Maternity and Children's Hospital of Quanzhou. The family has signed a written informed consent to take part in this study allowing for the use of the relevant data in scientific research.

\section{Consent for publication}

We confirm that the family has signed a written informed consent for publication of their own and their children's genetic data, clinical details, and/or any accompanying images.

\section{Competing interests}

The authors declare that they have no competing interests.

Received: 8 April 2020 Accepted: 6 October 2020

Published online: 13 October 2020

\section{References}

1. Nezu J, Tamai I, Oku A, Ohashi R, Yabuuchi H, Hashimoto N, Nikaido H, Sai Y, Koizumi A, Shoji Y, et al. Primary systemic carnitine deficiency is caused by mutations in a gene encoding sodium ion-dependent carnitine transporter. Nat Genet. 1999;21(1):91-4.

2. Magoulas PL, El-Hattab AW. Systemic primary carnitine deficiency: an overview of clinical manifestations, diagnosis, and management. Orphanet J Rare Dis. 2012;7:68.

3. Rasmussen J, Nielsen OW, Janzen N, Duno M, Gislason H, Kober L, Steuerwald U, Lund AM. Carnitine levels in 26,462 individuals from the nationwide screening program for primary carnitine deficiency in the Faroe Islands. J Inherit Metab Dis. 2014;37(2):215-22.

4. Rasmussen J, Duno M, Lund AM, Steuerwald U, Hansen SH, Joensen HD, Kober L, Nielsen OW. Increased risk of sudden death in untreated Primary Carnitine Deficiency. J Inherit Metab Dis. 2020;43(2):290-6.

5. Longo N. Primary Carnitine deficiency and newborn screening for disorders of the Carnitine cycle. Ann Nutr Metab. 2016;68(Suppl 3):5-9.

6. Saheki T, Kobayashi K. Mitochondrial aspartate glutamate carrier (citrin) deficiency as the cause of adult-onset type II citrullinemia (CTLN2) and idiopathic neonatal hepatitis (NICCD). J Hum Genet. 2002;47(7):333-41.

7. Tabata A, Sheng JS, Ushikai M, Song YZ, Gao HZ, Lu YB, Okumura F, lijima M, Mutoh K, Kishida S, et al. Identification of 13 novel mutations including a retrotransposal insertion in SLC25A13 gene and frequency of 30 mutations found in patients with citrin deficiency. J Hum Genet. 2008;53(6):534-45.

8. Lin Y, Liu Y, Zhu L, Le K, Shen Y, Yang C, Chen X, Hu H, Ma Q, Shi X, et al. Combining newborn metabolic and genetic screening for neonatal intrahepatic cholestasis caused by citrin deficiency. J Inherit Metab Dis. 2020;43(3):467-77.

9. Ohura T, Kobayashi K, Tazawa Y, Abukawa D, Sakamoto O, Tsuchiya S, Saheki T. Clinical pictures of 75 patients with neonatal intrahepatic cholestasis caused by citrin deficiency (NICCD). J Inherit Metab Dis. 2007; 30(2):139-44.

10. Okano $Y$, Ohura $T$, Sakamoto $O$, Inui A. Current treatment for citrin deficiency during NICCD and adaptation/compensation stages: strategy to prevent CTLN2. Mol Genet Metab. 2019;127(3):175-83.

11. Estrella J, Wilcken B, Carpenter K, Bhattacharya K, Tchan M, Wiley V. Expanded newborn screening in New South Wales: missed cases. J Inherit Metab Dis. 2014;37(6):881-7.

12. Han L, Wang F, Wang Y, Ye J, Qiu W, Zhang H, Gao X, Gong Z, Gu X. Analysis of genetic mutations in Chinese patients with systemic primary carnitine deficiency. Eur J Med Genet. 2014;57(10):571-5. 
13. Song $Y Z$, Zhang ZH, Lin WX, Zhao XJ, Deng M, Ma YL, Guo L, Chen FP, Long XL, He XL, et al. SLC25A13 gene analysis in citrin deficiency: sixteen novel mutations in east Asian patients, and the mutation distribution in a large pediatric cohort in China. PLoS One. 2013;8(9):e74544.

14. Abuduxikuer K, Chen R, Wang ZL, Wang JS. Risk factors associated with mortality in neonatal intrahepatic cholestasis caused by citrin deficiency (NICCD) and clinical implications. BMC Pediatr. 2019;19(1):18.

15. Tang NL, Hwu WL, Chan RT, Law LK, Fung LM, Zhang WM. A founder mutation (R254X) of SLC22A5 (OCTN2) in Chinese primary carnitine deficiency patients. Hum Mutat. 2002;20(3):232.

16. Lin WX, Zeng HS, Zhang ZH, Mao M, Zheng QQ, Zhao ST, Cheng Y, Chen FP, Wen WR, Song YZ. Molecular diagnosis of pediatric patients with citrin deficiency in China: SLC25A13 mutation spectrum and the geographic distribution. Sci Rep. 2016;6:29732.

17. Lin Y, Zheng Q, Zheng T, Zheng Z, Lin W, Fu Q. Expanded newborn screening for inherited metabolic disorders and genetic characteristics in a southern Chinese population. Clin Chim Acta. 2019;494:106-11.

18. Popek M, Walter M, Fernando M, Lindner M, Schwab KO, Sass JO. Two inborn errors of metabolism in a newborn: glutaric aciduria type I combined with isobutyrylglycinuria. Clin Chim Acta. 2010;411(23-24):2087-91.

19. Shibbani K, Fahed AC, Al-Shaar L, Arabi M, Nemer G, Bitar F, Majdalani M. Primary carnitine deficiency: novel mutations and insights into the cardiac phenotype. Clin Genet. 2014;85(2):127-37.

20. Yang CH, Chen CY, Chou YY, Chiu HC, Tsai WL, Shiesh SC. Bile acid profiles in neonatal intrahepatic cholestasis caused by citrin deficiency. Clin Chim Acta. 2017:475:28-35.

21. Fu HY, Zhang SR, Yu H, Wang XH, Zhu QR, Wang JS. Most common SLC25A13 mutation in 400 Chinese infants with intrahepatic cholestasis. World J Gastroenterol. 2010;16(18):2278-82.

22. Radhakrishna U, Albayrak S, Zafra R, Baraa A, Vishweswaraiah S, Veerappa AM, Mahishi D, Saiyed N, Mishra NK, Guda C, et al. Placental epigenetics for evaluation of fetal congenital heart defects: ventricular Septal defect (VSD). PLoS One. 2019;14(3):e0200229.

23. Kasuda S, Kudo R, Yuui K, Kondo T, Hatake K. Sudden unexpected infantile death due to undiagnosed ventricular septal defect-associated heart failure with single coronary artery. Forensic Sci Med Pathol. 2019;15(2):300-3.

\section{Publisher's Note}

Springer Nature remains neutral with regard to jurisdictional claims in published maps and institutional affiliations.

Ready to submit your research? Choose BMC and benefit from:

- fast, convenient online submission

- thorough peer review by experienced researchers in your field

- rapid publication on acceptance

- support for research data, including large and complex data types

- gold Open Access which fosters wider collaboration and increased citations

- maximum visibility for your research: over $100 \mathrm{M}$ website views per year

At $\mathrm{BMC}$, research is always in progress.

Learn more biomedcentral.com/submissions 